\title{
Expression of recombinant Rhipicephalus (Boophilus) microplus, $R$. annulatus and $R$. decoloratus $B m 86$ orthologs as secreted proteins in Pichia pastoris
}

\author{
Mario Canales ${ }^{1}$, José M Pérez de la Lastra1 ${ }^{1}$, Victoria Naranjo ${ }^{1}$, Ard M Nijhof ${ }^{2}$, \\ Michelle Hope ${ }^{3}$, Frans Jongejan ${ }^{2,4}$ and José de la Fuente*1,5
}

\begin{abstract}
Address: ${ }^{1}$ Instituto de Investigación en Recursos Cinegéticos IREC (CSIC-UCLM-JCCM), Ronda de Toledo s/n, 13071 Ciudad Real, Spain, ${ }^{2}$ Utrecht Centre for Tick-borne Diseases (UCTD), Department of Infectious Diseases and Immunology, Faculty of Veterinary Medicine, Utrecht University, Yalelaan 1, 3584CL, Utrecht, The Netherlands, ${ }^{3}$ CSIRO Livestock Industries, Queensland Bioscience Precinct, 306 Carmody Road, St. Lucia, Qld 4067, Australia, ${ }^{4}$ Department of Veterinary Tropical Diseases, Faculty of Veterinary Science, University of Pretoria, Private Bag X04, 0110, Onderstepoort, South Africa and ${ }^{5}$ Department of Veterinary Pathobiology, Center for Veterinary Health Sciences, Oklahoma State University, Stillwater, OK 74078, USA
\end{abstract}

Email: Mario Canales - mario.canales@uclm.es; José M Pérez de la Lastra - josemanuel.plastra@uclm.es;

Victoria Naranjo - mvictoria.naranjo@uclm.es; Ard M Nijhof - A.M.Nijhof@uu.nl; Michelle Hope - Shelly.Hope@csiro.au;

Frans Jongejan - Jongejan@uu.nl; José de la Fuente* - jose.de_la_fuente@okstate.edu

* Corresponding author

Published: I 4 February 2008

BMC Biotechnology 2008, 8:14 doi:10.1 |86/1472-6750-8-14
Received: 5 November 2007

Accepted: I4 February 2008

This article is available from: http://www.biomedcentral.com//472-6750/8/14

(c) 2008 Canales et al; licensee BioMed Central Ltd.

This is an Open Access article distributed under the terms of the Creative Commons Attribution License (http://creativecommons.org/licenses/by/2.0), which permits unrestricted use, distribution, and reproduction in any medium, provided the original work is properly cited.

\begin{abstract}
Background: Rhipicephalus (Boophilus) spp. ticks economically impact on cattle production in Africa and other tropical and subtropical regions of the world. Tick vaccines constitute a costeffective and environmentally friendly alternative to tick control. The R. microplus Bm86 protective antigen has been produced by recombinant DNA technology and shown to protect cattle against tick infestations.
\end{abstract}

Results: In this study, the genes for Bm86 (R. microplus), Ba86 (R. annulatus) and Bd86 (R. decoloratus) were cloned and characterized from African or Asian tick strains and the recombinant proteins were secreted and purified from P. pastoris. The secretion of recombinant Bm86 ortholog proteins in $P$. pastoris allowed for a simple purification process rendering a final product with high recovery $(35-42 \%)$ and purity $(80-85 \%)$ and likely to result in a more reproducible conformation closely resembling the native protein. Rabbit immunization experiments with recombinant proteins showed immune cross-reactivity between $\mathrm{Bm} 86$ ortholog proteins.

Conclusion: These experiments support the development and testing of vaccines containing recombinant $\mathrm{Bm} 86, \mathrm{Ba} 86$ and $\mathrm{Bd} 86$ secreted in P. pastoris for the control of tick infestations in Africa.

\section{Background}

Rhipicephalus (Boophilus) spp. ticks are distributed in tropical and subtropical regions of the world with range expansion for some species due to changes in climatic conditions [1-3]. Infestations with the cattle tick, Rhipicephalus (Boophilus) microplus, economically impact cattle production by reducing weight gain and milk production, and by transmitting pathogens that cause babesiosis 
(Babesia bovis and B. bigemina) and anaplasmosis (Anaplasma marginale) [4]. R. annulatus and $R$. decoloratus also affect cattle production and vector pathogens in regions of Latin America, Africa or Asia [2].

Control of tick infestations has been difficult because ticks have few natural enemies. Integrated tick management strategies include the adaptation of different control methods to a geographic area. A major component of integrated tick control methods is the application of acaricides. However, use of acaricides has had limited efficacy in reducing tick infestations and is often accompanied by serious drawbacks, including the selection of acaricideresistant ticks, environmental contamination and contamination of milk and meat products with drug residues [5]. Furthermore, development of new acaricides is a long and expensive process. All of these issues reinforce the need for alternative approaches to control tick infestations [5]. Other approaches proposed for tick control have included the use of hosts with natural resistance to ticks, pheromone-impregnated decoys for attracting and killing ticks, biological control agents and vaccines [6-8].

In the early 1990s, vaccines were developed that induced immunological protection of vertebrate hosts against tick infestations. These vaccines contained the recombinant $R$. microplus Bm86 gut antigen [8-12]. Two vaccines using recombinant Bm86 were subsequently registered in Latin American countries (Gavac) and Australia (TickGARD) during 1993-1997 [13]. These vaccines reduce the number of engorging female ticks, their weight and reproductive capacity. Thus the greatest vaccine effect was the reduction of larval infestations in subsequent generations. Vaccine controlled field trials in combination with acaricide treatments demonstrated that an integrated approach resulted in control of tick infestations while reducing the use of acaricides [12-14]. These trials demonstrated that control of ticks by vaccination has the advantages of being cost-effective, reducing environmental contamination and preventing the selection of drug resistant ticks that result from repeated acaricide application. In addition, these vaccines may also prevent or reduce transmission of pathogens by reducing tick populations and/or affecting tick vectorial capacity [13-15].

Controlled immunization trials have shown that $R$. microplus Bm86-containing vaccines also protect against related tick species, $R$. annulatus and $R$. decoloratus [16-18]. However, $R$. microplus strain-to-strain variations in the susceptibility to Bm86 vaccination have been reported, which suggests that Bm86 sequence and/or tick physiological differences may influence the efficacy of the vaccine $[8,19$ 22]. Therefore, the cloning, expression and vaccine formulation with recombinant $\mathrm{Bm} 86$ from local tick strains may be required for vaccine efficacy in some geographic regions [20].

The recombinant Bm86 has been expressed in Escherichia coli [10], Aspergillus nidulans and A. niger [23] and Pichia pastoris $[11,24,25]$. Of these expression systems, $P$. pastoris has been shown to be the more efficient for protein secretion $[26,27]$. Furthermore, production of Bm86 in P. pastoris may increase the antigenicity and immunogenicity of the recombinant antigen $[28,29]$. However, the process previously reported for the production of recombinant Bm86 in P. pastoris is not based on protein secretion but on the expression of the antigen anchored to the yeast membrane, making necessary the purification under denaturing conditions followed by refolding of an antigen with high number of disulfide bonds [24,25,30]. Recently, $R$. decoloratus Bm86 orthologs were cloned, expressed in E. coli and partially characterized [31]. However, the cloning and expression of recombinant $R$. annulatus and R. decoloratus $\mathrm{Bm} 86$ orthologs in P. pastoris have not been reported.

The objectives of this study were (i) to clone and express in $P$. pastoris the recombinant $R$. microplus, $R$. decoloratus and $R$. annulatus $\mathrm{Bm} 86$ orthologs from African or Asian tick strains and (ii) to simplify the Bm 86 production process by secreting recombinant proteins encoded by Bm 86 orthologs in P. pastoris.

\section{Results and Discussion}

\section{Cloning and sequence analysis of Bm86, Bd86 and Ba86}

The Bm86 orthologs were cloned by RT-PCR from Mozambique R. microplus (Bm86), Israeli R. annulatus (Ba86) and South African $R$. decoloratus (Bd86) tick strains. Partial sequences were obtained and used to search the NCBI nr database for sequence identity. The first four BLAST hits $(E$-value $=0.0)$ showed that cloned $\mathrm{Bm} 86, \mathrm{Bd} 86$ and Ba86 sequences were identical $(90-97 \%$ identity) to previously reported Bm86 (Australian Yeerongpilly reference strain; GenBank accession number $\underline{\text { M29321) }}$ Bm95 (Argentinean A strain; AF150891) and Bd86-1 and Bd86-2 (Kenyan strain; DQ630523 and DQ630524) sequences. The only fragment of 1,107 nucleotides previously reported for Ba86 (Mexican strain; AF150897) had $99.9 \%$ identity to the Ba86 sequence reported here with a single $A \times G$ substitution at position 1,674 (position 1 corresponds to the adenine in the initiation codon of the $\underline{M 29321}$ reference sequence). The Bm86 sequence of the Mozambique R. microplus strain reported here had a deletion of 66 nucleotides between positions 554 and 619 not found in other Bm86 sequences, which suggested that this region encoding for 22 amino acids may not be important for protein function. The Bd86 sequence of the South African R. decoloratus strain had an 18 nucleotides insertion between 
positions 1,690 and 1,691, similar to Bd86-2 and three nucleotides longer than in Bd86-1 [31].

Pairwise nucleotide and amino acid sequence alignments were conducted between cloned Bm86, Ba86 and Bd86 sequences and those identified above to have identity to these sequences (Table 1). The results showed that sequence identity was higher between $\mathrm{Bm} 86$ and $\mathrm{Ba} 86$ than with $\mathrm{Bd} 86$ sequences.

\section{Production and characterization of $P$. pastoris strains for} the expression of recombinant $\mathrm{Bm} 86, \mathrm{Bd} 86$ and $\mathrm{Ba} 86$

The plasmids pPAMoz9, pPADec 8 and $\mathrm{pBaI}$ were transformed into P. pastoris strains GS115, KM71H and X33 for expression of recombinant Bm86, Bd86 and Ba86 proteins. Single colonies of $P$. pastoris transformants for each gene were grown in an orbital shaker under induction conditions. Culture supernatants were spotted on a nitrocellulose membrane for dot-blot analysis of recombinant proteins. Expression of Bm86 and Bd86 was obtained in GS115 and KM71H strains while Ba86 was expressed in strain X33 only (Table 2). Expression levels varied between 1.0 and $6.0 \mathrm{mg} \cdot \mathrm{L}^{-1}$, representing $1.5 \%$ to $13.2 \%$ of total proteins in the supernatant (Table 2). For recombinant $\mathrm{Bm} 86$ and $\mathrm{Bd} 86$, differences in expression levels were not observed between GS115 and KM71H strains. The highest expression levels were obtained for Ba86 in strain X33 (Table 2). The recombinant strains GS115Moz9-2, KM71HDec8-1 and X33pBaI-3 with highest expression levels of $\mathrm{Bm} 86, \mathrm{Bd} 86$ and $\mathrm{Ba} 86$, respectively, were selected for fermentation scale up in a 5 - $\mathrm{L}$ bioreactor.

The GS115Moz9-2, KM71HDec8-1 and X33pBaI-3 high expression strains had a Mut ${ }^{\mathrm{S}}$ phenotype (Table 3 ). It has been demonstrated that transformation of $P$. pastoris with plasmids using the AOX1 expression system may lead to three mutant phenotypes with regard to methanol utilization [32]. The Mut ${ }^{+}$phenotype grows on methanol at the wild-type rate and requires high feeding rates of metha- nol, the Mut ${ }^{\mathrm{S}}$ phenotype has a disruption in the AOX1 gene and has a slower specific growth rate in methanol and the Mut is unable to grow in methanol. Although transformation of X-33 and GS115 strains with linearized constructs favor single crossover recombination at the AOX1 locus and generates a Mut ${ }^{+}$phenotype, double crossover recombination that results in the disruption of the wild-type $A O X 1$ gene and the generation of a Mut ${ }^{\mathrm{S}}$ phenotype is possible. The P. pastoris strains with a Mut ${ }^{\mathrm{S}}$ phenotype grow slower in methanol but may be better hosts for the secretion of recombinant proteins [33].

\section{Expression of recombinant Ba86, Bd86 and Bm86 proteins in $\mathrm{P}$. pastoris}

The GS115Moz9-2, KM71HDec8-1 and X33pBaI-3 strains were used for bench-top fermentation exploiting the methanol utilization ability of $P$. pastoris strains in PM medium. This medium was previously used for $P$. pastoris fermentations to express high levels of recombinant Bm86 [24,34].

The initial phase of the fermentation process (biomass production phase) ended after 20-24 hrs and induction of recombinant protein expression started at the onset of methanol-adoption and utilization phases. As expected, all strains behaved similarly when growing on glycerol as the sole carbon source (Table 3). Cell densities before induction and maximum growth rates on glycerol were very similar and similar to those previously reported in $P$. pastoris $[33,35]$.

The selected fed-batch strategy to feed methanol was identical for all strains. Once glycerol used as carbon source in the initial batch and fed-batch phases was consumed, recombinant protein expression was induced by the addition of methanol to the culture medium. An exponential growth phase was then observed during the next 20-24 hrs with maximum growth rates of $0.005,0.002$ and $0.003 \mathrm{~h}^{-1}$ for the strains GS115Moz9-2, KM71HDec8-1 and $\mathrm{X} 33 \mathrm{pBaI}-3$, respectively. However, after 24 hrs growth

Table I: Nucleotide and amino acid sequence comparison between Bm86 orthologs.

\begin{tabular}{|c|c|c|c|c|c|c|c|}
\hline & $\begin{array}{l}R m \text { Bm86 } \\
\text { (M2932I) }\end{array}$ & $\begin{array}{c}R m \text { Bm95 } \\
\text { (AFI5089I) }\end{array}$ & $\begin{array}{c}R m \text { Bm86 } \\
\text { (EUI91620) }\end{array}$ & $\begin{array}{c}R a \mathrm{Ba} 86 \\
\text { (EUI9162I) }\end{array}$ & $\begin{array}{c}R d \text { Bd86-2 } \\
\text { (DQ630524) }\end{array}$ & $\begin{array}{c}R d \text { Bd86-I } \\
\text { (DQ630523) }\end{array}$ & $\begin{array}{c}R d B d 86 \\
\text { (EU191622) }\end{array}$ \\
\hline Rm Bm86 (M2932I) & 100 & 99 & 94 & 96 & 90 & 90 & 90 \\
\hline Rm Bm95 (AFI5089I) & 98 & 100 & 94 & 96 & 90 & 90 & 90 \\
\hline Rm Bm86 (EUI9I620)* & 93 & 92 & 100 & 92 & 86 & 87 & 86 \\
\hline Ra Ba86 (EUI9I62I)* & 94 & 94 & 90 & 100 & 91 & 91 & 91 \\
\hline Rd Bd86-2 (DQ630524) & 85 & 86 & 82 & 87 & 100 & 96 & 97 \\
\hline Rd Bd86-I (DQ630523) & 86 & 86 & 82 & 88 & 94 & 100 & 96 \\
\hline Rd Bd86 (EUI91622)* & 86 & 87 & 82 & 88 & 96 & 94 & 100 \\
\hline
\end{tabular}

Percent identity among nucleotide (above diagonal) and percent similarity among deduced amino acid (below diagonal) sequences between Bm86 orthologs were determined. Sequences were aligned and percent identity/similarity was determined using the program AlignX. Abbreviations: $R m, R$. microplus; Ra, R. annulatus; $R d, R$. decoloratus. GenBank accession numbers are shown in parenthesis. The sequences reported in this study are identified wth an asterisk. 
Table 2: Screening for Bm86, Bd86 and Ba86 expression in the culture supernatant of $P$. pastoris transformants.

\begin{tabular}{|c|c|c|c|c|c|}
\hline Recombinant strain & Parental strain & $\begin{array}{l}\text { Recombinant } \\
\text { protein }\end{array}$ & $\begin{array}{l}\text { Total protein } \\
\text { concentration }\left(\mathrm{mg} \cdot \mathrm{L}^{-1}\right)^{\mathrm{a}}\end{array}$ & $\begin{array}{l}\text { Recombinant protein } \\
\text { concentration }\left(\mathrm{mg} \cdot \mathrm{L}^{-\mathrm{l}}\right)^{\mathrm{b}}\end{array}$ & $\begin{array}{l}\% \text { of total } \\
\text { proteinc }\end{array}$ \\
\hline GSII5Moz9-I & GSII5 & $\mathrm{Bm} 86$ & 66.5 & 3.0 & 4.5 \\
\hline GSII5Moz9-2* & GSII5 & $\mathrm{Bm} 86$ & 65.5 & 3.3 & 5.0 \\
\hline GSII5Moz9-3 & GSII5 & $\mathrm{Bm} 86$ & 65.3 & 1.0 & 1.5 \\
\hline KM7IHMoz9-I & KM7IH & $\mathrm{Bm} 86$ & 66.3 & 1.0 & 1.5 \\
\hline KM7IHMoz9-2 & KM7IH & $\mathrm{Bm} 86$ & 66.8 & 3.0 & 4.5 \\
\hline KM7IHMoz9-3 & KM7IH & $\mathrm{Bm} 86$ & 64.8 & 1.5 & 2.3 \\
\hline GSII5Dec8-I & GSII5 & Bd86 & 64.4 & 1.0 & 1.6 \\
\hline GSII5Dec8-2 & GSII5 & $\mathrm{Bd} 86$ & 66.4 & 1.5 & 2.3 \\
\hline GSII5Dec8-3 & GSII5 & Bd86 & 66.0 & 1.5 & 2.3 \\
\hline KM7IHDec8-I* & KM7IH & Bd86 & 66.0 & 2.0 & 3.0 \\
\hline KM7IHDec8-2 & KM7IH & $\mathrm{Bd} 86$ & 63.4 & 1.5 & 2.4 \\
\hline KM7IHDec8-3 & KM7IH & $\mathrm{Bd} 86$ & 63.5 & 1.0 & 1.6 \\
\hline X33pBal I & $\times 33$ & $\mathrm{Ba} 86$ & 49.7 & 1.0 & 2.0 \\
\hline X33pBal 2 & $\times 33$ & $\mathrm{Ba} 86$ & 45.5 & 1.0 & 2.2 \\
\hline X33pBal 3* & $\times 33$ & $\mathrm{Ba} 86$ & 45.4 & 6.0 & 13.2 \\
\hline X33pBall I & $\times 33$ & $\mathrm{Ba} 86$ & 55.8 & 5.5 & 9.8 \\
\hline X33pBall 2 & $\times 33$ & Ba86 & 48.3 & 5.0 & 10.4 \\
\hline X33pBall 3 & $\times 33$ & Ba86 & 46.9 & 4.0 & 8.5 \\
\hline
\end{tabular}

The experiments were conducted twice with similar results.

aDetermined using the Bradford method with BSA as standard [49].

bDetermined by semi-quantitative analysis in dot-blots using a standard curve constructed with known amounts of recombinant Bm86 extracted from Gavac (Revetmex).

cDetermined as the percent of recombinant protein in total preoteins.

*Recombinant strains with highest Bm86, Bd86 and Ba86 concentration in the culture supernatant were selected for fermentation and protein production.

in methanol, cells stop growing and a steady increase in $\mathrm{pO}_{2}$ levels revealed that a stationary growth phase was achieved. Nevertheless, total protein production continued to increase gradually to 274,194 and $170 \mathrm{mg} \cdot \mathrm{L}^{-1}$ for the strains GS115Moz9-2, KM71HDec8-1 and X33pBaI-3, respectively (Table 3 and Figs. 1 and 2).

In this first approach to obtain recombinant Bm86, Bd86 and Ba86 secreted to the culture medium, methanol was supplied at $1 \mathrm{ml} \cdot \mathrm{h}^{-1} \cdot \mathrm{L}$ of the initial fermentation volume for the first two hrs and then methanol supply was increased in $10 \%$ increments every $30 \mathrm{~min}$ to a rate of 3 $\mathrm{ml} \cdot \mathrm{h}^{-1} \cdot \mathrm{L}$. This strategy probably did not allow maintain- ing a steady concentration of methanol throughout the whole fermentation process and either starvation or accumulation of methanol could have occurred. This fact may explain lower growth rates and expression levels of recombinant Bm86, Bd86 and Ba86 when compared to the 65 $\mathrm{g} \cdot \mathrm{L}^{-1}$ dry weight and $1.5 \mathrm{~g} \cdot \mathrm{L}^{-1}$ of recombinant protein previously reported for membrane-bound $\mathrm{Bm} 86$ in P. pastoris $[11,24,34]$. These results suggest that recombinant Bm86, $\mathrm{Bd} 86$ and Ba86 protein expression levels may be increased by the optimization of the fermentation and methanol induction processes.

Table 3: Characterization of the fermentation process for the secretion of recombinant Bm86, Bd86 and Ba86.

\begin{tabular}{|c|c|c|c|c|c|c|c|c|}
\hline \multirow{2}{*}{$\begin{array}{l}\text { Recombinant } \\
\text { strain }\end{array}$} & \multirow{2}{*}{$\begin{array}{c}\text { Mut } \\
\text { phenotype }\end{array}$} & \multirow{2}{*}{$\begin{array}{c}\text { O.D. } 600 \mathrm{~nm} \text { before } \\
\text { induction }\end{array}$} & \multirow{2}{*}{$\mu_{\max } \underset{\left(\mathbf{h}^{-1}\right)^{\text {in }}}{\text { glycerol }}$} & \multirow{2}{*}{$\mu_{\max } \underset{\left(\mathbf{h}^{-1}\right)^{\mathbf{b}}}{\text { in methanol }}$} & \multirow{2}{*}{$\begin{array}{c}\text { Total protein } \\
\text { concentration } \\
\left(\mathbf{m g} \cdot \mathrm{L}^{-1}\right)^{\mathrm{c}}\end{array}$} & \multicolumn{3}{|c|}{ Recombinant protein } \\
\hline & & & & & & $\begin{array}{l}\text { Concentration } \\
\left(\mathrm{mg} \cdot \mathrm{L}^{-1}\right)^{\mathrm{c}}\end{array}$ & $\begin{array}{c}\text { Purity } \\
(\%)^{c}\end{array}$ & $\begin{array}{l}\text { Productivity } \\
\left(\mathbf{m g} \cdot \mathrm{L}^{-1} \cdot \mathbf{h}^{-1}\right)^{\mathrm{c}}\end{array}$ \\
\hline GSII5Moz9-2 & $\mathrm{Mut}^{\mathrm{S}}$ & 115 & 0.181 & 0.005 & 274 & 150 & 55 & 2.1 \\
\hline KM7IHDec8-I & Mut $^{S}$ & 125 & 0.182 & 0.002 & 194 & 110 & 57 & 1.5 \\
\hline X33pBal 3 & Mut $^{S}$ & 125 & 0.178 & 0.003 & 170 & 112 & 66 & 1.6 \\
\hline
\end{tabular}

aThe maximum growth rate $\left(\mu_{\max }\right)$ was determined during the exponential growth phase on glycerol in batch and fedbatch modes.

bThe maximum growth rate $\left(\mu_{\max }\right)$ was determined during the exponential growth phase on methanol (first $20-24$ hrs after induction).

'Determined in the culture medium 72 hrs after induction with methanol using the Bradford method with BSA as standard [49] and the Experion semiautomated

electrophoresis system (Bio-Rad, Hercules, CA, USA). 


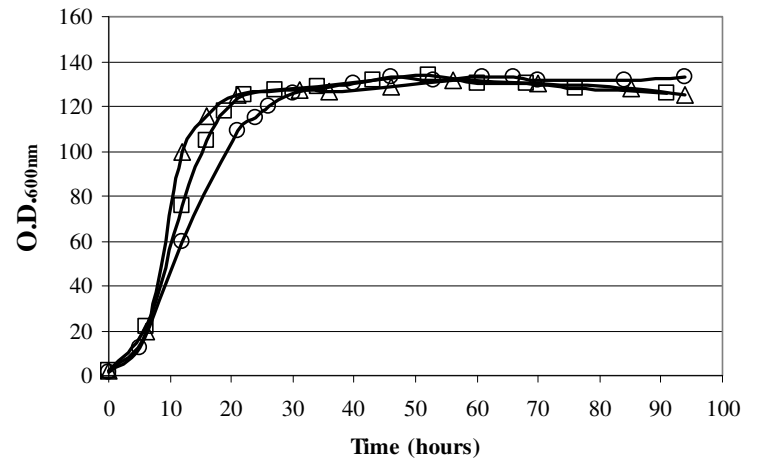

G GS 115Moz9-2 $\rightarrow$ KM71HDec8-1 $\triangle$ X33pBaI-3

Figure I

Characterization of the growth of $P$. pastoris strains during the fermentation process. Time profile of optical density measurements of $P$. pastoris strains GSI I5Moz9-2, KM7IHDec8-I and X33pBal-3 expressing recombinant $\mathrm{Bm} 86, \mathrm{Bd} 86$ and $\mathrm{Ba} 86$, respectively.

The presence of recombinant proteins in the culture supernatant was demonstrated at the end of the fermentation process by SDS-PAGE and Western blot (Fig. 3). Recombinant $\mathrm{Bm} 86, \mathrm{Bd} 86$ and $\mathrm{Ba} 86$ secreted in P. pastoris appeared in SDS-PAGE and Western blots as a major wide band with a size range of 100 to $110 \mathrm{kDa}$ and smaller degradation fragments (Fig. 3). The recombinant Bm86 previously expressed in $P$. pastoris also had degradation products and a major wide band, but with a size ranging

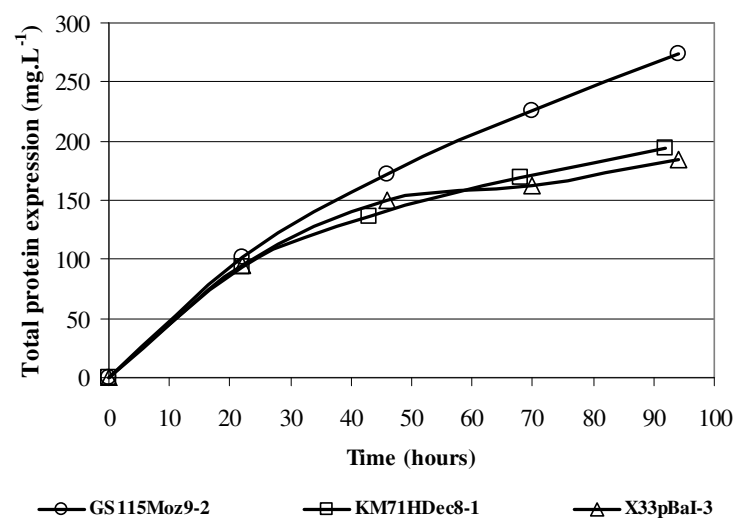

Figure 2

Characterization of protein secretion in $P$. pastoris strains during the fermentation process. Time profile of total protein concentration in the culture medium of $P$. pastoris strains GSI I 5Moz9-2, KM7IHDec8-I and X33pBal-3 expressing recombinant $\mathrm{Bm} 86, \mathrm{Bd} 86$ and $\mathrm{Ba} 86$, respectively.

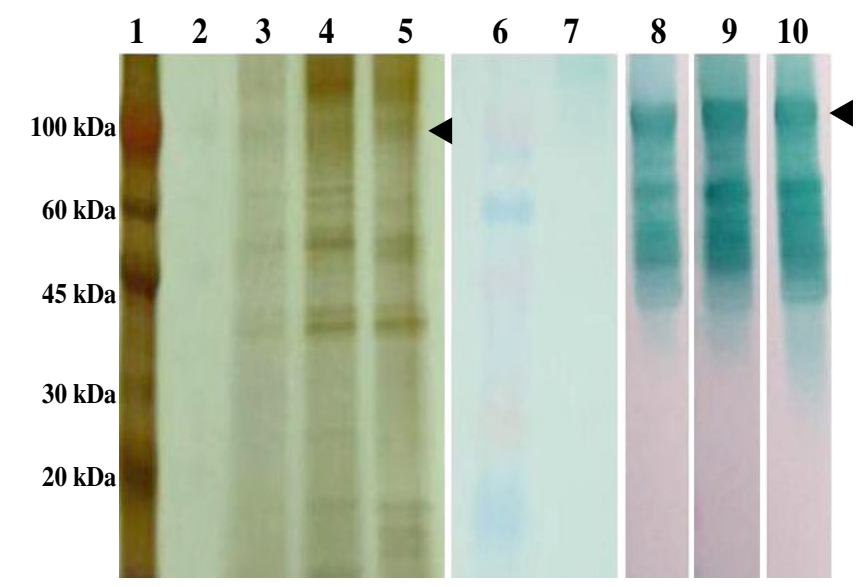

Figure 3

Secretion of recombinant $\mathrm{Bm} 86$, $\mathrm{Bd} 86$ and $\mathrm{Ba} 86$ by P. pastoris. Silver stained SDS-PAGE (lanes I-5) and Western blot analysis (lanes 6-10) of the fermentation culture supernatants after $72 \mathrm{hrs}$ growing in methanol. Samples of 15 $\mu \mathrm{L}$ were loaded in each well. Membranes for Western blot were probed with serum from rabbits immunized with control Bm86 (Gavac; Revetmex) diluted I: I000. Membranes were then washed three times with TBS and incubated with an anti-rabbit lgG HRP conjugate (Sigma-Aldrich) diluted $\mathrm{I}: 1000$ in TBS. After washing the membranes again, color was developed using TMB stabilized substrate for HRP (Promega). Lanes I and 6: molecular weight markers (MW; ColorBurst, Sigma-Aldrich). Lanes 2 and 7: culture supernatants of the $P$. pastoris GSI I5/Albumin negative control strain. Lanes 3 and 8,4 and 9 , and 5 and 10: culture supernatants of X33pBal-3 (Ba86), GSI I5Moz9-2 (Bm86) and KM7IHDec8-I (Bd86) strains, respectively. The position of recombinant proteins is indicated with arrows.

from 90 to $100 \mathrm{kDa}$ [11]. These differences in estimated molecular weight of the proteins may be due to strain differences in glycosylation, which is responsible for the wide appearance of the protein band in the SDS-PAGE and Western blot [11].

\section{Protein recovery and purification}

To obtain a clarified supernatant for recombinant protein purification, a primary centrifugation step was performed at $3,900 \times \mathrm{g}$. Due to the fact that $P$. pastoris culture centrifugation at g-forces between 3,000-5,000 results in a significant product entrainment [36], a washing step of cell pellets was made for the full recovery of secreted proteins.

P. pastoris secretes few autologous proteins [37]. Therefore, heterologous protein secretion serves as the major first step in recombinant protein purification. However, unclear supernatants and recombinant protein purities ranging between $55 \%$ and $66 \%$ suggested the presence of contaminants in the supernatant after cell separation 
(Table 4). This observation suggested that probably cell lysis occurred during the stationary phase of the fermentation process due to suboptimal growth conditions. Cell lysis during the fermentation may have contributed to protein degradation, thus affecting recombinant protein yield and reinforcing the need for optimization of the fermentation process to reduce protein degradation and increase expression levels.

It has been demonstrated in previous cell fractionation experiments of $P$. pastoris that a wide range of particles densities and sizes are present in a disrupted suspension of the yeast $[38,39]$. Therefore, to separate particles in suspension from secreted recombinant proteins, supernatants were filtered throughout 5, 0.45 and $0.22 \mu \mathrm{m}$ filtration systems, which resulted in $20-25 \%$ increase in recombinant protein purity (Table 4 ). Finally, size exclusion and diafiltration through a $50 \mathrm{kDa}$ cut-off membrane resulted in $80-85 \%$ pure recombinant proteins (Table 4 and Fig. 4).

The purity of recombinant proteins reported herein after protein secretion and a simple centrifugation-filtration purification process was higher than that obtained for membrane-bound Bm86 [24,34]. The purification of the membrane-bound Bm86 required cell disruption, washing of cell pellet, denaturation, renaturation and protein precipitation procedures $[24,34]$. In spite of the high level expression obtained during fermentation $[11,34]$ and the optimization of the purification process $[24,40-43]$ for the membrane-bound $\mathrm{Bm} 86$, the secretion of recombinant Bm86 in P. pastoris reported herein allowed for higher recovery and purity of recombinant protein after purification.

Additionally, an important advantage of secreting recombinant proteins in $P$. pastoris, particularly for proteins with complex structures and a high number of disulfide bonds such as Bm86 [44], is that the isolation of a membranebound form under denaturing conditions followed by refolding is very unlikely to reform all disulfide bonds correctly and reproducibly. By contrast, if disulfide bond formation occurs through the natural cell processing and secretion machinery as reported herein, the product is more likely to have a reproducible conformation closely resembling the native protein.

The recombinant Bm86 has been expressed in E. coli [10], A. nidulans and A. niger [23] and P. pastoris $[11,24,25]$. Other expression systems using arthropod cell lines have been considered. However, despite recent advances in the application of insect cell culture technology for the production of recombinant proteins, the process is still more expensive and difficult to scale-up when compared to proteins expressed in E. coli and P. pastoris [45]. The secretion of recombinant $\mathrm{Bm} 86$ ortholog proteins reported here in $P$. pastoris is easy to scale-up, simple, reproducible and likely to result in a product with high antigenicity and immunogenicity $[28,29]$.

\section{Characterization of recombinant Bm86, Bd86 and Ba86}

Although differences may exist in antigen recognition between cattle and rabbits [46], rabbits have been proven to recognize some $\mathrm{Bm} 86$ protective epitopes $[11,47]$ and were therefore considered a suitable host to evaluate immune cross-reactivity between recombinant Bm86 ortholog proteins.

The purified recombinant $\mathrm{Bm} 86, \mathrm{Bd} 86$ and $\mathrm{Ba} 86$ were adjuvated and used to immunize rabbits. The sera from immune rabbits were used to evaluate by Western blot the immune cross-reactivity between $\mathrm{Bm} 86$ ortholog proteins. The results showed that recombinant Bm86, Bd86 and Ba86 contained cross-reactive epitopes (Fig. 5). These results are in agreement with previous reports for Bd86 [31] and may explain, at least in part, the efficacy of the Bm86-containing vaccine against $R$. annulatus and $R$. decoloratus infestations [16-18]. However, despite immune cross-reactivity between Bm86 ortholog proteins, the differences in the efficacy of Bm86-containing vaccines against different Rhipicephalus spp. may be attributed to differences in the sequence of protective epitopes and/or physiological differences between tick species. Only cattle vaccination experiments with the recombinant antigens obtained here and challenging with homologous and heterologous Rhipicephalus spp. could fully address this question.

\section{Conclusion}

We have cloned and secreted in $P$. pastoris the recombinant $R$. microplus, $R$. decoloratus and $R$. annulatus $\mathrm{Bm} 86$ orthologs from African or Asian tick strains. To our knowledge, this is the first study of Bm86, Bd86 and Ba86 secretion in $P$. pastoris. The results reported herein have shown that in P. pastoris, Bm86 ortholog recombinant proteins are secreted and purified from the culture supernatant with high yield and purity. The purification process for secreted proteins was simpler than that described for membrane-bound Bm86, which suggests the possibility of simplifying the purification process for recombinant Bm86 when secreted in P. pastoris. Additionally, secretion of recombinant $\mathrm{Bm} 86$ ortholog proteins in $P$. pastoris is likely to result in a more reproducible conformation closely resembling the native protein. Finally, the preliminary immunological characterization of recombinant Bm86, Bd86 and Ba86 evidenced the presence of crossreactive epitopes among these proteins. These results suggest that these recombinant antigens can be used for the development of vaccines for the control of tick infestations in Africa. The control of livestock Rhipicephalus spp. 
Table 4: Characterization of the recombinant Bm86, Bd86 and Ba86 purification process.

\begin{tabular}{|c|c|c|c|c|c|c|c|c|c|c|c|c|}
\hline \multirow[t]{2}{*}{ Purification stages } & \multicolumn{4}{|c|}{ Bm86 } & \multicolumn{4}{|c|}{ Bd86 } & \multicolumn{4}{|c|}{ Ba86 } \\
\hline & $\begin{array}{l}\text { Total protein } \\
\text { conc. }\left(\mathrm{mg} \cdot \mathrm{L}^{-1}\right)\end{array}$ & $\begin{array}{l}\text { Rec. protein } \\
\text { conc. }\left(m g \cdot L^{-1}\right)\end{array}$ & $\begin{array}{l}\text { Purity } \\
\text { (\%) }\end{array}$ & $\begin{array}{l}\text { Recovery } \\
(\%)\end{array}$ & $\begin{array}{l}\text { Total protein } \\
\text { conc. }\left(\mathrm{mg} \cdot \mathrm{L}^{-1}\right)\end{array}$ & $\begin{array}{l}\text { Rec. protein } \\
\text { conc. }\left(m g \cdot L^{-1}\right)\end{array}$ & $\begin{array}{l}\text { Purity } \\
\text { (\%) }\end{array}$ & $\begin{array}{l}\text { Recovery } \\
(\%)\end{array}$ & $\begin{array}{l}\text { Total protein } \\
\text { conc. }\left(\mathrm{mg} \cdot \mathrm{L}^{-1}\right)\end{array}$ & $\begin{array}{l}\text { Rec. protein } \\
\text { conc. }\left(m g \cdot L^{-1}\right)\end{array}$ & $\begin{array}{l}\text { Purity } \\
(\%)\end{array}$ & $\begin{array}{l}\text { Recovery } \\
(\%)\end{array}$ \\
\hline Fermentation supernatant & 274 & 150 & 55 & --- & 194 & 110 & 57 & --- & 170 & 112 & 66 & --- \\
\hline $\begin{array}{l}\text { Culture separation and } \\
\text { microfiltration }\end{array}$ & 137 & 96 & 70 & 60 & 84 & 63 & 75 & 55 & 99 & 77 & 78 & 62 \\
\hline $\begin{array}{l}\text { Ultrafiltration and } \\
\text { diafiltration }\end{array}$ & 407 & 326 & 80 & 35 & 451 & 370 & 82 & 42 & 370 & 314 & 85 & 40 \\
\hline
\end{tabular}

Abbreviations: conc., concentration; rec., recombinant. 


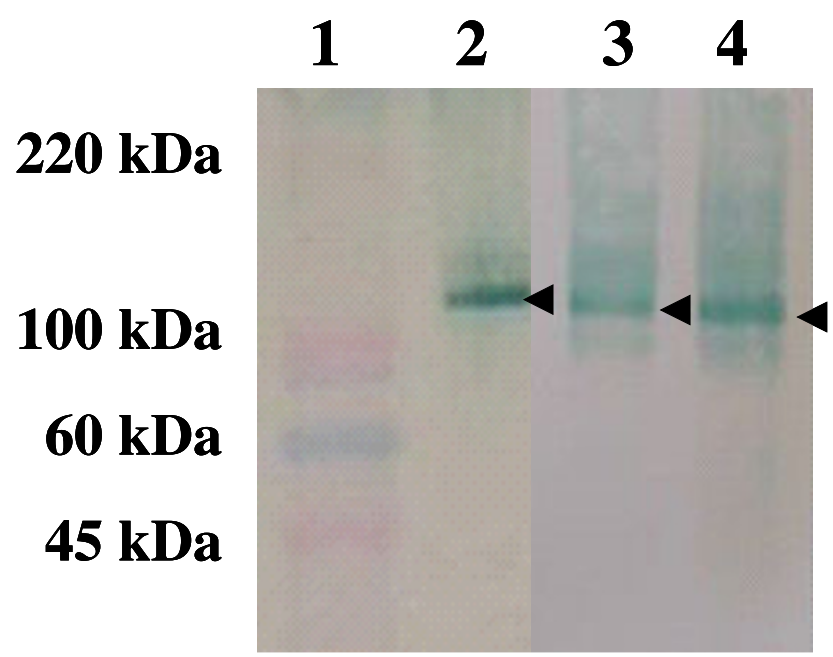

\section{Figure 4}

Characterization of purified recombinant proteins. Western blot analysis of the purified recombinant $\mathrm{Bm} 86$ (lane 2), Bd86 (lane 3) and Ba86 (lane 4) proteins. On each well, $3.5 \mu \mathrm{g}$ proteins were loaded. Membranes were probed with serum from rabbits immunized with control Bm86 (Gavac; Revetmex) diluted I:1000. Membranes were then washed three times with TBS and incubated with an anti-rabbit IgG HRP conjugate (Sigma-Aldrich) diluted I:I000 in TBS. After washing the membranes again, color was developed using TMB stabilized substrate for HRP (Promega). Lane I: molecular weight markers (MW; ColorBurst, Sigma-Aldrich). The position of recombinant proteins is indicated with arrows.

infestations in Africa would contribute to improve animal health and production in this region.

\section{Methods}

\section{Media and solutions}

All reagents used in this work were purchased from SigmaAldrich (St Louis, MO, USA) or VWR International Eurolab S.L. (Mollet del Vallés, Barcelona, Spain). The compositions of the media used in this study were as follows:

Minimal methanol medium (MM): $13.4 \mathrm{~g} \cdot \mathrm{L}^{-1}$ yeast nitrogen base with ammonium sulphate and without amino acids (YNB); $0.0004 \mathrm{~g} \cdot \mathrm{L}^{-1}$ biotin; $15 \mathrm{~g} \cdot \mathrm{L}^{-1}$ agar and $0.5 \%$ methanol.

Minimal methanol medium + Histidine $(\mathrm{MMH}): 13.4$ $\mathrm{g} \cdot \mathrm{L}^{-1} \mathrm{YNB} ; 0.0004 \mathrm{~g} \cdot \mathrm{L}^{-1}$ biotin; $15 \mathrm{~g} \cdot \mathrm{L}^{-1}$ agar; $0.04 \mathrm{~g} \cdot \mathrm{L}^{-1}$ histidine and $0.5 \%$ methanol.

Minimal dextrose medium (MD): $13.4 \mathrm{~g} \cdot \mathrm{L}^{-1} \mathrm{YNB} ; 0.0004$ $\mathrm{g} \cdot \mathrm{L}^{-1}$ biotin; $15 \mathrm{~g} \cdot \mathrm{L}^{-1}$ agar and $20 \mathrm{~g} \cdot \mathrm{L}^{-1}$ dextrose.

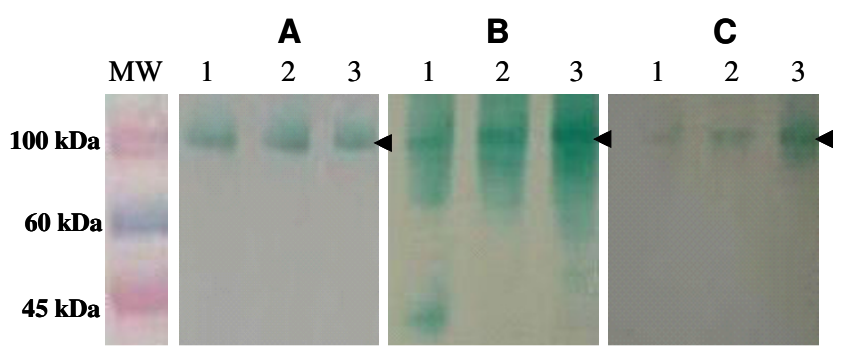

Figure 5

Immune cross-reactivity between Bm86 ortholog proteins. Western blot analysis of the purified recombinant Ba86 (lane I), Bd86 (lane 2) and Bm86 (lane 3) proteins. On each well I.5 $\mu$ g proteins were loaded. Membranes were probed with serum from rabbitts immunized with recombinant Ba86 (A), Bd86 (B) and Bm86 (C) diluted I:5000. Membranes were washed three times with TBS and incubated with an anti-rabbit IgG HRP conjugate (Sigma-Aldrich) diluted I:I000 in TBS. After washing the membrane again, color were developed using TMB stabilized substrate for HRP (Promega). MW: molecular weight marker (ColorBurst, Sigma-Aldrich). The position of recombinant proteins is indicated with arrows.

Minimal dextrose medium + Histidine $(\mathrm{MDH}): 13.4 \mathrm{~g} \cdot \mathrm{L}-$ ${ }^{1} \mathrm{YNB}$; $0.0004 \mathrm{~g} \cdot \mathrm{L}^{-1}$ biotin; $15 \mathrm{~g} \cdot \mathrm{L}^{-1}$ agar; $20 \mathrm{~g} \cdot \mathrm{L}^{-1}$ dextrose and $20 \mathrm{~g} \cdot \mathrm{L}^{-1}$ dextrose.

Yeast Extract Peptone medium (YP): $10 \mathrm{~g} \cdot \mathrm{L}^{-1}$ yeast extract and $20 \mathrm{~g} \cdot \mathrm{L}^{-1}$ peptone.

Yeast Extract Peptone Dextrose medium (YPD): $10 \mathrm{~g} \cdot \mathrm{L}^{-1}$ yeast extract; $20 \mathrm{~g} \cdot \mathrm{L}^{-1}$ peptone and $20 \mathrm{~g} \cdot \mathrm{L}^{-1}$ glucose.

Yeast Extract Peptone Dextrose Sorbitol medium (YPDS): $10 \mathrm{~g} \cdot \mathrm{L}^{-1}$ yeast extract; $20 \mathrm{~g} \cdot \mathrm{L}^{-1}$ peptone; $20 \mathrm{~g} \cdot \mathrm{L}^{-1}$ glucose; $182 \mathrm{~g} \cdot \mathrm{L}^{-1}$ sorbitol and $20 \mathrm{~g} \cdot \mathrm{L}^{-1}$ agar.

Trace element solution (TES): $2.0 \mathrm{~g} \cdot \mathrm{L}^{-1} \mathrm{ZnSO}_{4} \times 7 \mathrm{H}_{2} \mathrm{O}$; $0.02 \mathrm{~g} \cdot \mathrm{L}^{-1} \mathrm{CuSO}_{4} \times 5 \mathrm{H}_{2} \mathrm{O} ; 0.08 \mathrm{~g} \cdot \mathrm{L}^{-1} \mathrm{KI} ; 0.3 \mathrm{~g} \cdot \mathrm{L}^{-1} \mathrm{MnSO}_{4}$ $\times \mathrm{H}_{2} \mathrm{O} ; 0.19 \mathrm{~g} \cdot \mathrm{L}^{-1} \mathrm{Na}_{2} \mathrm{MoO}_{4} \times \mathrm{H}_{2} \mathrm{O} ; 0.02 \mathrm{~g} \cdot \mathrm{L}^{-1} \mathrm{H}_{3} \mathrm{BO}_{3}$ and $2.9 \mathrm{~g} \cdot \mathrm{L}^{-1} \mathrm{FeCl}_{3}$.

Vitamin solution (VT): $0.4 \mathrm{~g} \cdot \mathrm{L}^{-1}$ calcium pantothenate; $0.4 \mathrm{~g} \cdot \mathrm{L}^{-1}$ tyamine; $4 \mathrm{~g} \cdot \mathrm{L}^{-1}$ myo-inositol; $0.1 \mathrm{~g} \cdot \mathrm{L}^{-1}$ nicotinic acid; $0.4 \mathrm{~g} \cdot \mathrm{L}^{-1}$ pyridoxine and $0.4 \mathrm{~g} \cdot \mathrm{L}^{-1}$ biotin.

Production medium (PM): $13 \mathrm{~g} \cdot \mathrm{L}^{-1} \mathrm{KH}_{2} \mathrm{PO}_{4} ; 8.75 \mathrm{~g} \cdot \mathrm{L}^{-1}$ $\left(\mathrm{NH}_{4}\right)_{2} \mathrm{SO}_{4} ; 4.5 \mathrm{~g} \cdot \mathrm{L}^{-1} \mathrm{MgSO}_{4} ; 0.5 \mathrm{~g} \cdot \mathrm{L}^{-1} \mathrm{CaCl}_{2} \times 2 \mathrm{H}_{2} \mathrm{O} ; 2.5$ $\mathrm{g} \cdot \mathrm{L}^{-1}$ yeast extract; $5 \mathrm{ml} \cdot \mathrm{L}^{-1}$ TES and $5 \mathrm{ml} \cdot \mathrm{L}^{-1} \mathrm{VT}$. 
Cloning of R. microplus, R. annulatus and R. decoloratus Bm86 orthologs and sequence analysis

Tick strains were obtained from laboratory colonies maintained at the Utrecht Centre for Tick-borne Diseases, Department of Infectious Diseases and Immunology, Faculty of Veterinary Medicine, Utrecht University, Utrecht, The Netherlands. Originally, tick strains were collected from infested cattle in Mozambique (R. microplus), Israel (R. annulatus) and South Africa ( $R$. decoloratus).

Total RNA was extracted from the viscera of partially fed $R$. annulatus and $R$. microplus females and from eggs of $R$. annulatus and $R$. decoloratus using TriReagent (SigmaAldrich, St Louis, MO, USA) and following manufacturer's recommendations. Bm86 (R. microplus), Ba86 (R. annulatus) and $\mathrm{Bd} 86$ (R. decoloratus) coding regions (nucleotides 58-1884 of the coding region of Bm86 reference sequence; GenBank accession number M29321) lacking the signal peptide and GPI anchor sequences were amplified by RT-PCR. The RT-PCR was done using 10 pmol of each primer (CZABM5: 5'-A CTC GAG AAA AGA GAG TCA TCC ATT TGC TCT GAC TTC GG and CZABM3: 5'-A TCT AGA TTA AGC ACT TGA CTT TCC AGG ATC TG; Bm86 homologous regions are underlined) in a $50-\mu \mathrm{l}$ volume $\left(1.5 \mathrm{mM} \mathrm{MgSO}{ }_{4} 1 \times\right.$ avian myeloblastosis virus (AMV) RT/Thermus flavus (Tfl) reaction buffer, $0.2 \mathrm{mM}$ each deoxynucleoside triphosphate (dNTP), 5 u AMV RT, $5 \mathrm{u}$ Tfl DNA polymerase) employing the Access RT-PCR system (Promega, Madison, WI, USA). Reactions were performed in an automated DNA thermal cycler (Techne model TC-512, Cambridge, England, UK). RNA was reverse transcribed for $45 \mathrm{~min}$ at $45^{\circ} \mathrm{C}$ prior to PCR consisting of an initial step of $2 \mathrm{~min}$ at $94^{\circ} \mathrm{C}$ followed by 35 cycles of a denaturing step of $30 \mathrm{sec}$ at $94^{\circ} \mathrm{C}$ and an annealing-extension step of $2 \mathrm{~min}$ at $68^{\circ} \mathrm{C}$. Control reactions were done using the same procedures, but without RNA added to control contamination of the PCR. PCR products were electrophoresed on 1\% agarose gels to check the size of amplified fragments by comparison to a DNA molecular weight marker (1 Kb Plus DNA Ladder, Promega). The amplicon was resin purified (Wizard, Promega) and cloned into pGEM-T vector (Promega). Partial sequences of cloned Bm86 orthologs were obtained by double-stranded dye-termination cycle sequencing (Core Sequencing Facility, Department of Biochemistry and Molecular Biology, Noble Research Center, Oklahoma State University and Secugen S.L, Madrid, Spain). At least three clones from independent PCR reactions were sequenced for each gene. Multiple sequence alignment was performed using the program AlignX (Vector NTI Suite V 8.0, InforMax, Invitrogen, Carlsbad, CA, USA) with an engine based on the Clustal W algorithm [48]. Searches for sequence similarity were performed at the ncbi with the BLASTN program against the nonredundant sequence database nr.
The GenBank accession numbers for Bm86 (R. microplus), $\mathrm{Ba} 86$ ( $R$. annulatus) and $\operatorname{Bd} 86(R$. decoloratus) are EU191620-EU191622.

\section{Construction of expression plasmids}

Bm86, Ba86 and Bd86 coding regions were excised from pGEM-T by Xho I and Xba I digestion (restriction sites introduced during PCR by CZABM5 and CZABM3 primers, respectively) and cloned into $P$. pastoris expression vector pPICZ $\alpha \mathrm{A}$ (Invitrogen) digested with $\mathrm{Xba}$ I and Xho I. In this way, Bm86 orthologs were cloned under the control of the alcohol oxidase (AOX1) promoter, in frame with the yeast alfa-factor secretion signal but without the C-terminal c-myc/His tag due to a translation termination site introduced by CZABM3 primer during PCR. The expression constructs were sequenced at both ends and selected constructs with correct sequences were named pPAMoz9 (Bm86), pPADec8 (Bd86) and pBaI (Ba86) and used for transformation of $P$. pastoris.

\section{Pichia pastoris transformation and screening for recombinant protein expression}

Expression plasmids were linearized by restriction with Sac I and transformed into P. pastoris strains GS115, $\mathrm{KM} 71 \mathrm{H}$ and X33 (Invitrogen) by electroporation as described [49]. Transformants were selected on YPDS plates containing $100 \mu \mathrm{g} \cdot \mathrm{ml}^{-1}$ Zeocin and incubated at $30^{\circ} \mathrm{C}$. A functional assay to directly screen for high expression recombinant clones was made by culturing the transformants in an orbital shaker at $250 \mathrm{rpm}$ and $30^{\circ} \mathrm{C}$. Single colonies were inoculated in $1 \mathrm{ml}$ YPDS containing 100 $\mu \mathrm{g} \cdot \mathrm{ml}^{-1}$ Zeocin and grown overnight. Cultures were divided into two parts of $500 \mu \mathrm{l}$ each. Five hundred $\mu \mathrm{l}$ were transferred to $5 \mathrm{ml}$ fresh YP medium with $20 \mathrm{~g} \cdot \mathrm{L}^{-1}$ glycerol, grown for $24 \mathrm{hrs}$ and inoculated into $250 \mathrm{ml}$ fresh YP medium supplemented with $20 \mathrm{~g} \cdot \mathrm{L}^{-1}$ glycerol. Growth in glycerol was resumed after $24 \mathrm{hrs}$ and then methanol was added daily to $1 \%(\mathrm{v} / \mathrm{v})$ during the course of induction. After 5 days growing on methanol, supernatants were collected by centrifugation for $15 \mathrm{~min}$ at $15,000 \times \mathrm{g}$ in a Beckman Allegra ${ }^{\mathrm{TM}} \mathrm{X}-22 \mathrm{R}$ centrifuge, rotor F2402H (Beckman-Coulter, Palo Alto, CA, USA) and dot blots were made to screen for expression of recombinant proteins. The other $500 \mu \mathrm{l}$ were also transferred to $5 \mathrm{ml}$ fresh YP medium with $20 \mathrm{~g} \cdot \mathrm{L}^{-1}$ glycerol, grown for $24 \mathrm{hrs}$ and mixed with glycerol to $250 \mathrm{~g} \cdot \mathrm{L}^{-1}$. Long term stocks were prepared as $100 \mu \mathrm{l}$ aliquots and stored frozen at $80^{\circ} \mathrm{C}$.

\section{Analysis of the Mut phenotype in P. pastoris transformed strains}

The high expression transformants of X33 and GS115 strains were analyzed for $\mathrm{Mut}^{+}$or $\mathrm{Mut}^{\mathrm{S}}$ phenotype using the functional assay described in the Invitrogen user's manuals K1710-01 and K1750-01 [49]. The KM71H 
strain always produces a Mut ${ }^{\mathrm{s}}$ phenotype [49]. Briefly, 50 $\mu \mathrm{l}$ from the long term stocks of the high expression X33 and GS115 transformants were streaked in YPDS plates containing $100 \mu \mathrm{g} \cdot \mathrm{ml}^{-1}$ Zeocin and incubated at $30^{\circ} \mathrm{C}$ for $24 \mathrm{hrs}$. One colony of each transformant was streaked in both MMH and MDH plates for the GS115 and X33 strains. To differentiate $\mathrm{Mut}^{+}$from $\mathrm{Mut}^{\mathrm{s}}$, control GS115/ Albumin $\left(\mathrm{Mut}^{\mathrm{S}}\right)$ and GS115/pPicz/lacZ $\left(\mathrm{Mut}^{+}\right)$strains (Invitrogen) were streaked in the MMH and MDH plates. Plates were incubated at $30^{\circ} \mathrm{C}$ for 3 days and cell growth was observed and compared to controls.

\section{Fermentation process}

Pre-inoculums and inoculums for bioreactor cultures were grown in a shaker at $30^{\circ} \mathrm{C}$ and $250 \mathrm{rpm}$. Two $100 \mu \mathrm{l}$ long term stock vials were seeded in $1 \mathrm{ml}$ YP medium, grown for $12 \mathrm{hrs}$ and transferred into $4 \times 50 \mathrm{ml}$ tubes containing $5 \mathrm{ml}$ of YP medium with $20 \mathrm{~g} \cdot \mathrm{L}^{-1}$ glycerol. After 24 hrs, cultures were mixed again and $5 \mathrm{ml}$ were used to inoculate $2 \mathrm{~L}$ Erlenmeyer flasks containing $250 \mathrm{ml}$ of YP medium with $20 \mathrm{~g} \cdot \mathrm{L}^{-1}$ glycerol. Cells were grown to an O.D. ${ }_{600} \mathrm{~nm}$ between 15 and 20 and then cultures were inoculated into a 5 - $\mathrm{L}$ working volume Biostat $\mathrm{B}$ bioreactor (B. Braun Biotech, Melsungen, Germany) containing 3.5 L of PM with $40 \mathrm{~g} \cdot \mathrm{L}^{-1}$ glycerol.

During the fermentation process, temperature was kept at $30{ }^{\circ} \mathrm{C}$ and dissolved oxygen was maintained at $30 \%$ saturation by regulating agitation and aeration rates. A threephase cultivation protocol was used in the fermentation. The glycerol growth phase included a 12 to 14 hrs batch stage from the starting point followed by a 10 to $12 \mathrm{hrs}$ glycerol fed-batch stage. A glycerol solution of $50 \%(\mathrm{v} / \mathrm{v})$ was added to the fermentor for 4 hrs to reach an equivalent total quantity of $60 \mathrm{~g} \cdot \mathrm{L}^{-1}$ in the culture medium. Upon exhaustion of glycerol, indicated by a sharp increase in dissolved oxygen, methanol induction was made by adding $1 \%(\mathrm{v} / \mathrm{v})$ methanol to the culture medium and 3 hrs later the fed-batch phase was started by feeding methanol according to the P. pastoris Fermentation Process Guideline [49]. The $\mathrm{pH}$ was allowed to drop to 3.5 during the whole glycerol phase and it was maintained in this value by the addition of $\mathrm{NH}_{4} \mathrm{OH}$. Prior to methanol induction, $\mathrm{pH}$ was adjusted and maintained at 5.5 by adding $\mathrm{NH}_{4} \mathrm{OH}$ or $\mathrm{H}_{3} \mathrm{PO}_{3}$. Throughout the fermentation processes, supplements of $20 \mathrm{ml}$ TES and VT solutions were added to the culture medium every $24 \mathrm{hrs}$. Additionally, GS115 strain cultures were supplemented with 0.04 $\mathrm{g} \cdot \mathrm{L}^{-1} \mathrm{~L}$-Histidine every $24 \mathrm{hrs}$.

\section{Biomass analysis during fermentation}

Time-course samples were withdrawn from the fermentor at regular intervals to check growth rate and protein concentration in the supernatant. Cell density was expressed

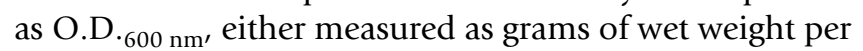

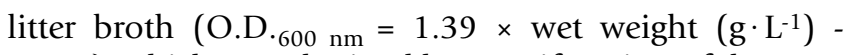
27.26), which was obtained by centrifugation of the samples at $15,000 \times \mathrm{g}$ for $15 \mathrm{~min}$ or measured directly in the culture medium. Total protein concentration in the culture medium was quantified using the Bradford method with BSA as standard [50].

\section{Cells harvesting, recovery and purification of recombinant proteins}

Cultures from the 5-L fermentor were centrifuged at 3,900 $\times \mathrm{g}$ for $15 \mathrm{~min}$ in a Beckman Allegra ${ }^{\mathrm{TM}} \mathrm{X}-22 \mathrm{R}$ centrifuge, rotor SX4250 (Beckman-Coulter) to separate cells. Supernatants were then collected and filtered through a tandem filtration system with a $20 \mu \mathrm{m}$ cartridge (Sartorius AG, Goettingen, Germany), $5 \mu \mathrm{m}$ and 0.45-0.22 $\mu \mathrm{m}$ cartridges (Millipore, Billerica, MA, USA) and checked for total and recombinant protein content using the Bradford method with BSA as standard [50] and the Experion semiautomated electrophoresis system (Bio-Rad, Hercules, CA, USA). For the Experion, $4 \mu \mathrm{l}$ of denatured proteins were loaded into a Pro 260 Chip and protein concentration was determined following manufacturer's recommendations. Recombinant proteins were separated by size exclusion using a Sartocon ${ }^{\varpi}$ Slice 200 ultrafiltration system having a Hydrosart membrane with a molecular weight cut-off of $50 \mathrm{kDa}$ (Sartorius). Finally, protein solutions were concentrated and diafiltrated against four volumes of phosphate buffer $\mathrm{pH} 8.3$ using a centrifugal concentrator VIVACELL 100 (50 kDa cut-off; Sartorius) in a Beckman Allegra $^{\mathrm{TM}}$ X-22R centrifuge, rotor SX4250 (Beckman-Coulter) at 3,900 $\times \mathrm{g}$.

\section{Vaccine formulation and analysis}

Prior to adjuvation of the vaccine, protein solutions were adjusted to a concentration of $120 \mu \mathrm{g} \cdot \mathrm{ml}^{-1}$ and filtered through 0.45 and $0.22 \mu \mathrm{m}$ cartridges (Sartorius AG) under sterile conditions in a laminar flow to obtain a sterile antigen solution. Adjuvation was made by mixing a solution of anhydromannitoletheroctodecenoate (Montanide ISA 50 V; Seppic, Paris, France) with the recombinant protein solution in batch-by-batch processes using a high-speed mixer Heidolph DIAX 900 (Heidolph Elektro, Kelheim, Germany) at 8,000 rpm and the vaccine was filled manually under sterile conditions in glass bottles of $20 \mathrm{ml}$ (Wheaton, Millville, NJ, USA). Quality controls were made by testing mechanical and thermal stability of vaccine emulsions as described by Canales et al. [24].

\section{Rabbit immunization with recombinant proteins}

Two New Zealand White rabbits per group was each immunized with 3 doses (weeks 0,4 and 8 ) containing 50 $\mu \mathrm{g} /$ dose of purified recombinant proteins formulated as described above or Gavac (Revetmex, Mexico City, Mexico) as control. Rabbits were injected subcutaneously with $1 \mathrm{ml} /$ dose using a $1 \mathrm{ml}$ tuberculin syringe and a $271 / 2 \mathrm{G}$ 
needle. Two weeks after the last immunization, blood samples were collected from each rabbit into sterile tubes and maintained at $4{ }^{\circ} \mathrm{C}$ until arrival at the laboratory. Serum was then separated after centrifugation and stored at $-20^{\circ} \mathrm{C}$. Rabbits were cared for in accordance with standards specified in the Guide for Care and Use of Laboratory Animals.

\section{SDS-PAGE, dot blot and Western blot analyses}

Protein samples were analyzed by denaturing SDS-PAGE with a $12 \%$ PAGEgel-SDS cassette gel (PAGE-gel Inc, San Diego, CA, USA) under reducing conditions. Protein bands were visualized by either Coomassie Brilliant Blue R250 or silver staining. Samples were treated with dithiothreitol (DTT) reducer (PAGE-gel Inc.), heated in boiling water for 5 min before loading onto the gel and electrophoresed for $80 \mathrm{~min}$ at $90 \mathrm{~mA}$ constant current.

Electrophoretic transfer of proteins from gels to nitrocellulose membranes (PROTRAN BA85; Schleicher and Schuell, Dassel, Germany) for Western blot analysis was carried out in a Minie-Genie Electroblotter semi-dry transfer unit (Idea Scientific, Corvallis, OR, USA) according to manufacture's protocol. Protein samples of $2 \mu \mathrm{l}$ were absorbed onto nitrocellulose membrane by gravity flow to perform the dot blot analysis. A standard curve was constructed with known amounts of recombinant Bm86 extracted from Gavac (Revetmex) and was used for semiquantitative analysis in dot-blots. The supernatant of the GS115/Albumin strain (Invitrogen) grown under the same conditions was used as a negative control in both dot- and Western-blots. Membranes for dot or Western blots were blocked with 5\% skim milk for $1 \mathrm{hr}$ at room temperature, washed three times in TBS $(25 \mathrm{mmol} / \mathrm{L}$ Tris $\cdot \mathrm{HCl}, 150 \mathrm{mmol} / \mathrm{L} \mathrm{NaCl}, \mathrm{pH} 7.6)$ and probed with sera from rabbits immunized with Gavac (Revetmex) (1:1000 dilution) or recombinant proteins (1:5000 dilution) as described above. The antisera were diluted in 3\% BSA in TBS. Membranes were then washed three times with TBS and incubated with an anti-rabbit IgG horseradish peroxidase (HRP) conjugate (Sigma-Aldrich) diluted 1:1000 in TBS. After washing the membranes again, color was developed using TMB stabilized substrate for HRP (Promega).

\section{Authors' contributions}

MC carried out the expression, fermentation and protein purification and characterization studies. JMPL, VN and AMN carried out the genetic studies and participated in the sequence alignment. MH participated in the design of the study and helped to draft the manuscript. JF did the sequence alignment. FJ and JF conceived the study, and participated in its design and coordination and helped to draft the manuscript. All authors read and approved the final manuscript.

\section{Acknowledgements}

We thank Peter Willadsen (CSIRO Livestock Industries, Queensland, Australia) for comments and suggestions to the work presented in this paper and to Leon Fourie (ClinVet, Bloemfontein, South Africa) and Varda Shkap (Division of Parasitology, Kimron Veterinary Institute, Bet Dagan, Israel) for providing the $R$. decoloratus and $R$. microplus and $R$. annulatus tick strains, respectively. This work was supported by the Wellcome Trust under the Animal Health in the Developing World initiative through project 0757990 entitled "Adapting recombinant anti-tick vaccines to livestock in Africa" and the Consejería de Educación y Ciencia, JCCM, Spain (project PAI06-00465285) and was facilitated through the Integrated Consortium on Ticks and Tick-borne Diseases (ICTTD-3), financed by the International Cooperation Program of the European Union, coordination action project No. 51056I. V. Naranjo was funded by Junta de Comunidades de Castilla - La Mancha (JCCM), Spain.

\section{References}

I. Barker SC, Murrell A: Systematics and evolution of ticks with a list of valid genus and species names. Parasitol 2004, 129:SI5-S36.

2. Estrada-Peña A, Bouattour A, Camicas JL, Guglielmone A, Horak I, Jongejan F, Latif A, Pegram R, Walker AR: The known distribution and ecological preferences of the tick subgenus Boophilus (Acari: Ixodidae) in Africa and Latin America. Exp Appl Acarol 2006, 38:219-235.

3. Olwoch JM, Van Jaarsveld AS, Scholtz CH, Horak IG: Climate change and the genus Rhipicephalus (Acari: Ixodidae) in Africa. Onderstepoort J Vet Res 2007, 74:45-72.

4. Peter RJ, Van den Bossche P, Penzhorn BL, Sharp B: Tick, fly, and mosquito control-Lessons from the past, solutions for the future. Vet Parasitol 2005, 132:205-2 I5.

5. Graf JF, Gogolewski R, Leach-Bing N, Sabatini GA, Molento MB, Bordin EL, Arantes GJ: Tick control: an industry point of view. Parasitol 2004, I 29:S427-S442.

6. de la Fuente J, Kocan KM: Strategies for development of vaccines for control of ixodid tick species. Parasite Immunol 2006, 28:275-283.

7. Sonenshine DE, Kocan KM, de la Fuente J: Tick control: further thoughts on a research agenda. Trends Parasitol 2006, 22:550-551.

8. Willadsen P: Tick control: thoughts on a research agenda. Vet Parasitol 2006, 138: 161-168.

9. Willadsen P, Riding GA, McKenna RV, Kemp DH, Tellam RL, Nielsen JN, Lahstein J, Cobon GS, Gough JM: Immunological control of a parasitic arthropod: identification of a protective antigen from Boophilus microplus. J Immunol I989, I 43:| 346-I35I.

10. Rand KN, Moore T, Sriskantha A, Spring K, Tellam R, Willadsen P, Cobon G: Cloning and expression of a protective antigen from the cattle tick Boophilus microplus. Proc Natl Acad Sci USA 1989, 86:9657-966I.

1I. Rodríguez M, Rubiera R, Montesinos R, Cremata JA, Falcón V, Sanchez G, Bringas R, Cordovés C, Valdés M, Lleonart R, Herrera L, de la Fuente J: High level expression of the B microplus Bm86 antigen in the yeast $P$. pastoris forming highly inmunogenic particles for cattle. J Biotechnol 1994, 33: 135-146.

12. de la Fuente J, Kocan KM: Advances in the identification and characterization of protective antigens for development of recombinant vaccines against tick infestations. Expert Rev Vaccines 2003, 2:583-593.

13. de la Fuente J, Almazán C, Canales M, Pérez de la Lastra JM, Kocan $K M$, Willadsen P: A ten-year review of commercial vaccine performance for control of tick infestations on cattle. Anim Health Res Rev 2007, 8:23-28.

14. de la Fuente J, Rodríguez M, Redondo M, Montero C, García-García JC, Méndez L, Serrano E, Valdés M, Enríquez A, Canales M, Ramos E, de Armas CA, Rey S, Rodríguez JL, Artiles M, García L: Field studies and cost-effectiveness analysis of vaccination with Gavac ${ }^{\mathrm{TM}}$ against the cattle tick Boophilus microplus. Vaccine 1998, 16:366-373.

15. Rodríguez Valle M, Méndez L, Valdez M, Redondo M, Espinosa CM, Vargas M, Cruz RL, Barrios HP, Seoane G, Ramírez ES, Boué O, Vigil $J$ L, Machado H, Nordelo CB, Piñeiro MJ: Integrated control of 
Boophilus microplus ticks in Cuba based on vaccination with the anti-tick vaccine Gavac. Exp Appl Acarol 2004, 34:375-382.

16. Fragoso $H$, Hoshmand Rad P, Ortiz M, Rodríguez M, Redondo M, Herrera L, de la Fuente J: Protection against Boophilus annulatus infestations in cattle vaccinated with the $B$. microplus Bm86containing vaccine Gavac. Vaccine 1998, 16:1990-1992.

17. de la Fuente J, Rodríguez M, Garcia-Garcia JC: Immunological control of ticks through vaccination with Boophilus microplus gut antigens. Ann N Y Acad Sci 2000, 916:617-621.

18. de Vos S, Zeinstra L, Taoufik O, Willadsen P, Jongejan F: Evidence for the utility of the Bm86 antigen from Boophilus microplus in vaccination against other tick species. Exp Appl Acarol $200 \mathrm{I}$ 25:245-26I.

19. García-García JC, González IL, González DM, Valdés M, Méndez L, Lamberti J, D'Agostino B, Citroni D, Fragoso H, Ortiz M, Rodríguez $M$, de la Fuente J: Sequence variations in the Boophilus microplus Bm86 locus and implications for immunoprotection in cattle vaccinated with this antigen. Exp Appl Acarol 1999, 23:883-895.

20. García-García JC, Montero C, Redondo M, Vargas M, Canales M, Boué $O$, Rodríguez M, Joglar M, Machado $H$, González IL, Valdés $M$, Méndez $L$, de la Fuente J: Control of ticks resistant to immunization with $\mathrm{Bm} 86$ in cattle vaccinated with the recombinant antigen $\mathrm{Bm} 95$ isolated from the cattle tick, Boophilus microplus. Vaccine 2000, I 8:2275-2287.

2I. de la Fuente J, García-García JC, González DM, Izquierdo G, Ochagavia ME: Molecular analysis of Boophilus spp. (Acari: Ixodidae) tick strains. Vet Parasitol 2000, 92:209-222.

22. Sossai S, Peconick AP, Sales-Junior PA, Marcelino FC, Vargas MI, Neves ES, Patarroyo JH: Polymorphism of the bm86 gene in South American strains of the cattle tick Boophilus microplus. Exp Appl Acarol 2005, 37: 199-2I4.

23. Turnbull IF, Smith DR, Sharp PJ, Cobon GS, Hynes MJ: Expression and secretion in Aspergillus nidulans and Aspergillus niger of a cell surface glycoprotein from the cattle tick, Boophilus microplus, by using the fungal amdS promoter system. App Environ Microbiol 1990, 56:2847-2852.

24. Canales M, Enriquez A, Ramos E, Cabrera D, Dandie H, Soto A, Falcon $\mathrm{V}$, Rodríguez $\mathrm{M}$, de la Fuente J: Large-scale production in Pichia pastoris of the recombinant vaccine Gavac ${ }^{\mathrm{TM}}$ against cattle ticks. Vaccine 1997, I5:4|4-422.

25. Boue O, Farnos O, Gonzalez A, Fernandez R, Acosta JA, Valdes R, Gonzalez LJ, Guanche Y, Izquierdo G, Suarez M, Dominguez I, Machado $\mathrm{H}$, Rodriguez M, Lleonart R: Production and biochemical characterization of the recombinant Boophilus microplus Bm95 antigen from Pichia pastoris. Exp Appl Acarol 2004, 32:119-128.

26. Cregg JM, Vedvick TS, Raschke WC: Recent advances in the expression of foreign genes in Pichia pastoris. Bio/Technology 1993, I I:905-910.

27. Zhang W, Sinha J, Smith LA, Inan M, Meaguer MM: Maximization of production of secreted recombinant proteins in Pichia pastoris fed-batch fementation. Biotechnol Prog 2005, $21: 386-393$

28. García-García JC, Montero C, Rodríguez M, Soto A, Redondo M, Valdés $M$, Méndez $L$, de la Fuente J: Effect of particulation on the immunogenic and protective properties of the recombinant Bm86 antigen expressed in Pichia pastoris. Vaccine 1998 , 16:374-380.

29. García-García JC, Soto A, Nigro F, Mazza M, Joglar M, Hechevarría M, Lamberti J, de la Fuente J: Adjuvant and immunostimulating properties of the recombinant $\mathrm{Bm} 86$ protein expressed in Pichia pastoris. Vaccine 1998, 16:1053-1055.

30. Rodriguez Valle M, Montero C, Machado H, Joglar M, de la Fuente J, Garcia-Garcia JC: The evaluation of yeast derivatives as adjuvants for the immune response to the $\mathrm{Bm} 86$ antigen in cattle. BMC Biotechnol 200I, I:3. Erratum in: BMC Biotechnol 200I, I: 3

31. Odongo D, Kamau L, Skilton R, Mwaura S, Nitsch C, Musoke A Taracha E, Daubenberger C, Bishop R: Vaccination of cattle with TickGARD induces cross-reactive antibodies binding to conserved linear peptides of Bm86 homologues in Boophilus decoloratus. Vaccine 2007, 25:1287-1296.

32. Macauley-Patrick S, Fazenda ML, Mcneil B, Harvey LM: Heterologous protein production using the Pichia pastoris expression system. Yeast 2005, 22:249-270.

33. Cos O, Resina D, Ferrer P, Montesinos JL, Valero F: Heterologous production of Rhizopus oryzae lipase in Pichia pastoris using the alcohol oxidase and formaldehyde dehydrogenase promotores in batch and fed-batch cultures. Biochem Eng J 2005, 26:86-94.

34. Enriquez A, Canales M, Ramos E, Dandie H, Boué O, Soto A, Cabrera $D$ : Production of a recombinant vaccine against Boophilus microplus. In Recombinant Vaccines for the Control of Cattle Tick Edited by: de la Fuente J. La Habana, Elfos Scientiae; 1995:79-103.

35. Zhang W, Potter KJH, Plantz BA, Schlegel VL, Smith LA, Meagher MM: Pichia pastoris fermentation with mixed-feeds of glycerol and methanol: growth kinetics and production improvement. J Ind Microbiol Biotechnol 2003, 30:210-215.

36. Thömmes J, Halfar $M$, Gieren $H$, Curvers $S$, Takors $R$, Brunschier $R$, Kula MR: Human chymotrypsinogen $B$ production from Pichia pastoris by integrated development of fermentation and downstream processing. Part 2. Protein recovery. Biotechnol Prog 200I, 17:503-512.

37. Cregg JM, Madden KR, Barringer KJ, Thill GP, Stillman CA: Functional characterisation of the two alcohol oxidase genes from the yeast Pichia pastoris. Mol Cell Biol 1989, 9:1316-1323.

38. Liu H, Tan X, Russell KA, Veenhuis M, Cregg JM: PER3, a gene required for peroxisome biogenesis in Pichia pastoris, encodes a peroxisomal membrane protein involved in protein import. J Biol Chem 1995, 270: 10940-1095I.

39. Waterham HR, de Vries Y, Russell KA, Xie W, Veenhuis M, Cregg JM: The Pichia pastoris PER6 gene product is a peroxisomal integral membrane protein essential for peroxisome biogenesis and has sequence similarity to the Zellweger syndrome protein PAF-I. Mol Cell Biol 1996, 16:2527-2536.

40. Canales M, Buxadó JA, Heynnegnezz L, Enriquez A: Mechanical disruption of Pichia pastoris yeast to recover the recombinant glycoprotein Bm86. Enzyme Microb Technol 1998, 23:58-63.

4I. Canales M, de la Fuente J: Mechanical disruption of the yeast Pichia pastoris grown in methanol. Minerva Biotechnol 2006, 18:|37-144.

42. Boué O, Sanchez K, Tamayo G, Hernandez L, Reytor E, Enriquez A: Single-step purification of recombinant $B m 86$ produced in Pichia pastoris by salting-out and acid precipitation of contaminants. Biotechnol Techniques 1997, I I:56 I-565.

43. Buxadó JA, Heynngnezz LE, Juiz AG, Tamayo G, Lima IR, Marshalleck $\mathrm{HD}$, Mola EL: Scale-up of processes to isolate the misstargeted rBm86 protein from Pichia pastoris. Afr J Biotechnol 2004, 3:559-605.

44. Montesino R, Cremata J, Rodríguez M, Besada V, Falcón V, de la Fuente J: Biochemical characterization of the recombinant B.microplus Bm86 antigen obtained from Pichia pastoris expressing cells. Biotechnol Appl Biochem 1996, 23:23-28.

45. Agathos SN: Development of serum-free media for lepidopteran insect cell lines. Methods Mol Biol 2007, 388: 155-186.

46. Garcia-Garcia JC, de la Fuente J, Kocan KM, Blouin EF, Halbur T, Onet VC, Saliki' JT: Mapping of B-cell epitopes in the N-terminal repeated peptides of Anaplasma marginale major surface protein $I a$ and characterization of the humoral immune response of cattle immunized with recombinant and whole organism antigens. Vet Immunol Immunopathol 2004, 98: |37-I5 I.

47. Patarroyo JH, Portela RW, De Castro RO, Pimentel JC, Guzman F, Patarroyo ME, Vargas MI, Prates AA, Mendes MA: Immunization of cattle with synthetic peptides derived from the Boophilus microplus gut protein (Bm86). Vet Immunol Immunopathol 2002, 88: $163-172$.

48. Thompson JD, Higgins DG, Gibson TJ: CLUSTAL W: improving the sensitivity of progressive multiple sequence alignment through sequence weighting, positions-specific gap penalties and weight matrix choice. Nucl Acid Res 1994, 22:4673-4680.

49. Invitrogen user's manuals KI7IIO-0I and KI750-0I [http:// www.invitrogen.com]

50. Bradford $\mathrm{M}$ : A rapid and sensitive method for the quantitation of microgram quantities of protein utilizing the principle of protein-dye binding. Anal Biochem 1976, 72:248-254. 